\title{
Management Strategies for Dealing With Surges of the COVID-19 Pandemic
}

\author{
A.V. Raveendran ${ }^{1,2}$, Jothydev Kesavadev ${ }^{3}$, Parameswaran Hari ${ }^{4}$, Gopika Krishnan ${ }^{3}$ \\ 1. Internal Medicine, Government Medical College, Kozhikode, IND 2. Internal Medicine, Badr Al Samaa Hospital, \\ Barka, OMN 3. Diabetes and Endocrinology, Jothydev's Diabetes Research Centre, Thiruvananthapuram, IND 4. \\ Hematology and Oncology, Medical College of Wisconsin, Wauwatosa, USA
}

Corresponding author: A.V. Raveendran, raveendranav@yahoo.co.in

\begin{abstract}
The spread of COVID-19 (coronavirus disease 2019) across the world has resulted in widespread morbidity and mortality. An explosive increase in the number of cases during the surge phase of the pandemic can result in a management crisis. Therefore, we propose a simple model to manage the surges of the pandemic.
\end{abstract}

Review began 06/02/2021 Review ended 06/17/2021 Published 06/21/2021

๑) Copyright 2021

Raveendran et al. This is an open access article distributed under the terms of the Creative Commons Attribution License CC-BY 4.0., which permits unrestricted use, distribution, and reproduction in any medium, provided the original author and source are credited.
Categories: Internal Medicine, Infectious Disease, Public Health

Keywords: covid-19, sars-cov-2, pandemic, management, home treatment

\section{Introduction}

SARS-CoV-2 (severe acute respiratory syndrome coronavirus 2) infection, which started in Wuhan, China has by now spread all over the world causing widespread morbidity and mortality. An explosive increase in the number of cases occurs during the surges of the pandemic when even developed countries fail to accommodate and manage it properly. In addition to the shortage of hospital beds, ICU beds, ventilators, oxygen, and essential drugs, even the number of health care providers becomes insufficient to provide care in most situations of explosive spread. During the peak of the pandemic, similar crises have been reported from all parts of the world. To tide over the crisis, health care workers are forced to work continuously and still fail to address the issues. Proper planning and anticipation can help to utilize the resources more efficiently thereby enabling the provision of appropriate care to a larger number of citizens.

\section{Technical Report}

As of 17 May 2021, the total number of cases of COVID-19 (coronavirus disease 2019) in India is around $25,227,970$ and around 3,50,000 new cases are being added to this daily during the peak of the ongoing second wave [1]. Patients with a severe disease along with hypoxia require ventilators for an average of three to six days which can even be extended for weeks and to top this, new critical cases are also added every day resulting in a severe shortage of ventilators, oxygen supply, essential medicines, and hospital beds. However, only about 1.9 million hospital beds, 95,000 ICU beds, and 48,000 ventilators are available in India to fight against this crisis [2].

We propose a simple model to manage a pandemic surge, as even a well-established health system may fail to accommodate a large number of cases (Figure 1 and Table 1 ). 


\section{Cureus}

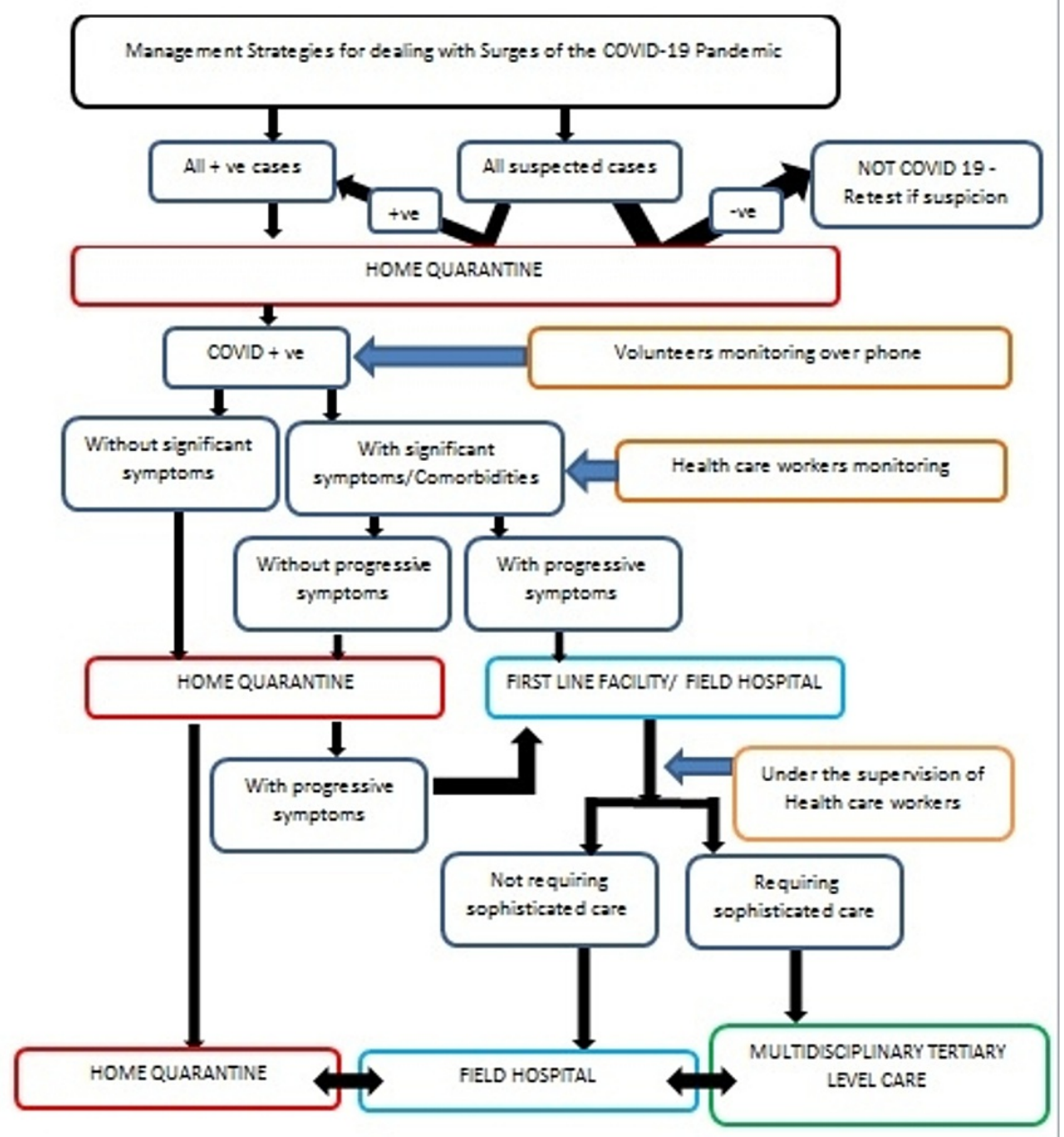

FIGURE 1: Proposed model to manage the surges of the pandemic 


\section{Cureus}

\begin{tabular}{|c|c|c|}
\hline Symptoms & Monitoring & Treatment \\
\hline \multicolumn{3}{|l|}{ At-home quarantine } \\
\hline Fever & \multirow{2}{*}{ Temperature } & Paracetamol \\
\hline Body ache & & Anti-histamines \\
\hline Headache & \multirow{2}{*}{ Pulse rate } & Antibiotics \\
\hline Running nose & & Cough syrup \\
\hline Cough & \multirow{2}{*}{ Respiratory rate } & H2 blockers/PPI \\
\hline Throat pain & & Steroids \\
\hline \multicolumn{3}{|l|}{ Breathlessness } \\
\hline Abdominal discomfort & Diood pressure & Anti-coagulants \\
\hline Diarrhea & Oxygen saturation (SpO2) & \\
\hline Any co-morbidities & $\begin{array}{l}\text { Full blood count, inflammatory markers, and biochemical } \\
\text { panels if healthcare workers visit }\end{array}$ & $\begin{array}{l}\text { Optimization of treatment of } \\
\text { co-morbidities }\end{array}$ \\
\hline \multicolumn{3}{|l|}{ At first line facility/ field hospital } \\
\hline \multirow{5}{*}{ Breathlessness } & All of the above & All of the above \\
\hline & Chest X-ray & Inj. Dexamethasone \\
\hline & Routine blood test including inflammatory markers and & $\begin{array}{l}\text { Monoclonal antibody- Inj. } \\
\text { Tocilizumab }\end{array}$ \\
\hline & biochemical panels & Inj. Heparin \\
\hline & & Oxygen \\
\hline Deterioration of comorbid condition & Monitoring of comorbidities & $\begin{array}{l}\text { Optimization of treatment of } \\
\text { comorbidities }\end{array}$ \\
\hline \multicolumn{3}{|l|}{ At multidisciplinary tertiary level care } \\
\hline \multirow{2}{*}{$\begin{array}{l}\text { Breathlessness even at maximal } \\
\text { oxygen supplementation }\end{array}$} & All of the above & All of the above \\
\hline & Investigations as per patients profile & Ventilator support \\
\hline Deterioration of comorbid condition & Monitoring of comorbidities & $\begin{array}{l}\text { Optimization of treatment of } \\
\text { comorbidities }\end{array}$ \\
\hline Early identification of complications & Monitoring of complications & Treatment of complications \\
\hline
\end{tabular}

\section{TABLE 1: Monitoring and treatment options of COVID-19 at different levels}

H2 blocker: Histamine-2 receptor blocker; PPI: Proton pump inhibitor; COVID-19: Coronavirus disease 2019.

\section{Discussion}

The majority of people affected with COVID-19 develop only asymptomatic or mildly symptomatic disease [3, 4]. Those who develop mild COVID-19 should be monitored and treated at home by trained family members or volunteers, with intermittent support from healthcare providers. The latter may recommend simple treatment measures like paracetamol, antihistamines, cough syrup, etc (Figure 2) [5]. Managing asymptomatic and uncomplicated cases (which constitute the majority of the cases during this pandemic) at home is the key step in the success of the management strategy. 


\section{Cureus}

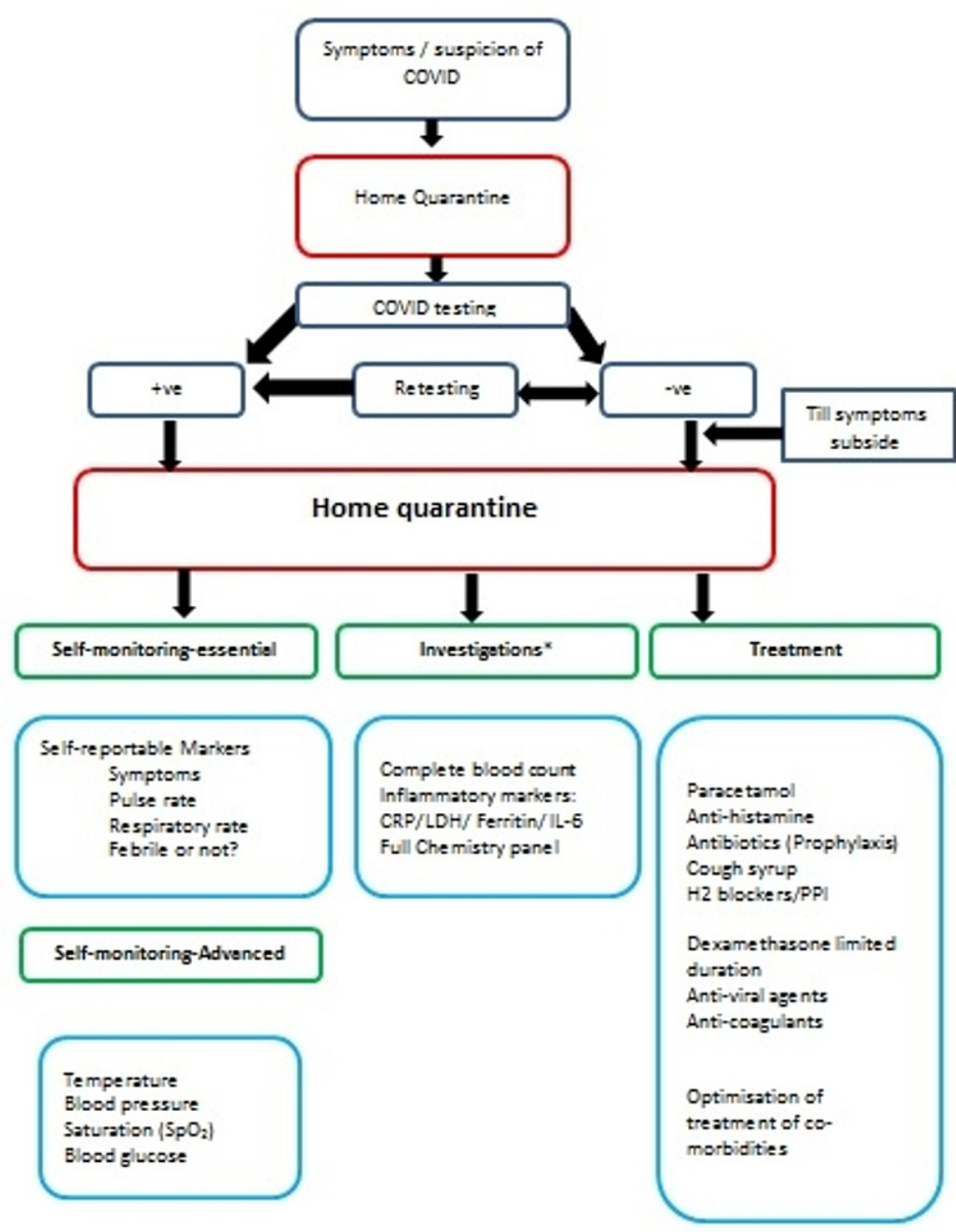

FIGURE 2: Treatment options during home quarentine

Those who have significant symptoms or associated co-morbidities should be monitored more closely by trained paramedical staff under the supervision of a doctor. The latter may administer drugs like antibiotics, anticoagulants, steroids, etc., depending upon the clinical scenario. Finally, those with moderate-to-severe COVID-19 or deteriorating symptoms such as hypoxia requiring oxygen should be shifted to hospitals, where volunteers, paramedical staff, and doctors are at hand to take care of these patients. Those developing hypoxia despite oxygen support may require positive-pressure ventilation support or multi-disciplinary interventions. Therefore, they should be shifted to tertiary-care facilities. We propose that this strategy will reduce unnecessary hospital admissions and resource utilization, thereby helping appropriate allocation of scarce resources to needy patients.

\section{Conclusions}

The adoption of the approach suggested by us will allow effective management of the pandemic, reduce unnecessary hospital admissions and expenditure, enable triaging of cases, and allow optimal engagement of healthcare professionals, thereby reducing the mortality and morbidity associated with the pandemic.

\section{Additional Information}

\section{Disclosures}

Human subjects: All authors have confirmed that this study did not involve human participants or tissue. Animal subjects: All authors have confirmed that this study did not involve animal subjects or tissue. Conflicts of interest: In compliance with the ICMJE uniform disclosure form, all authors declare the 


\section{Cureus}

following: Payment/services info: All authors have declared that no financial support was received from any organization for the submitted work. Financial relationships: All authors have declared that they have no financial relationships at present or within the previous three years with any organizations that might have an interest in the submitted work. Other relationships: All authors have declared that there are no other relationships or activities that could appear to have influenced the submitted work.

\section{References}

1. India. (2021). Accessed: May 17, 2021: https://www.worldometers.info/coronavirus/country/india/.

2. Kapoor G, Hauck S, Sriram A et al.: State-wise estimates of current hospital beds, intensive care unit (ICU) beds and ventilators in India: Are we prepared for a surge in COVID-19 hospitalizations?. medRxiv. 2020,

3. Kim GU, Kim MJ, Ra SH, Lee J, Bae S, Jung J, Kim SH: Clinical characteristics of asymptomatic and symptomatic patients with mild COVID-19. Clin Microbiol Infect. 2020, 26:948.e1-3. 10.1016/j.cmi.2020.04.040

4. Park PG, Kim CH, Heo Y, Kim TS, Park CW, Kim CH: Out-of-Hospital Cohort Treatment of Coronavirus Disease 2019 Patients with Mild Symptoms in Korea: an Experience from a Single Community Treatment Center. J Korean Med Sci. 2020, 35:e140. 10.3346/jkms.2020.35.e140

5. World Health Organization: Home care for patients with suspected or confirmed COVID-19 and management of their contacts: interim guidance, 12 August. World Health Organization, Geneva; 2020. http://WHO/2019-nCoV/IPC/HomeCare/2020.4. 